\title{
Social vulnerability to natural and technological hazards: The relevance of scale
}

\author{
J.M. Mendes \\ Centre for Social Studies, Faculty of Economics, University of Coimbra, Portugal
}

A.O. Tavares

Centre for Social Studies, Faculty of Sciences and Technology, University of Coimbra, Portugal

S. Freiria

Centre for Social Studies, University of Coimbra, Portugal

L. Cunha

Centre of Geographical Studies, Faculty of Humanities, University of Coimbra, Portugal

\begin{abstract}
In this paper it is proposed a new version of social vulnerability indexes to natural and technological hazards that takes into account, beyond the standard analysis of exposure or biophysical vulnerability, social resilience and infrastructural support capabilities. It also intends to be a contribution to the revision of established paradigms of disaster analysis, emphasizing the importance of social cartography about vulnerable communities and citizens, social resilience and infrastructural support capabilities. It contributes also to effective prevention and public security policies that take into account territorial cohesion and social inequalities. We present an evaluation of social vulnerability for all municipalities in Portugal, taking the national framework as reference, and also an evaluation of social vulnerability at the town level within a regional framework. The regional evaluation required a selection of seven municipalities in the Centre region of Portugal, according to their biophysical and socio-economics characteristics to represent an adequate sample for a new scale approach.
\end{abstract}

\section{INTRODUCTION}

Several authors (Cutter, 2003; Davis, 2004; Schmidtlein et al., 2008) and institutions (EMA, 2002; UNO, 2004) work in the social vulnerability field, evidencing its importance. Nevertheless, it is our contention that the existing methodologies to calculate social vulnerability do not take into account the social resilience of individuals, groups and communities. In this article we present a social vulnerability index that integrates support capability and criticality of the territorial system, at a municipal and town scale.

In Portugal there are few works concerning the use of social vulnerability indexes. There is a pioneer article written by Ribeiro (1995), proposing statistical methodologies of evaluation, and more recently Mendes (2009), who developed a Social Vulnerability Index for the Centre Region of Portugal.

Concerning Portuguese conditions, we may indicate several events (such as the winter floods on 2000/2001, the forest fires of 2003 and the heat waves of 2003 and 2006, the first with a total of 2100 deaths and the second with 1600 deaths), in which communities showed high levels of social vulnerability and individuals and families weren't prepared for such extreme conditions. It is our belief that a cartography analysis of the most vulnerable areas, and the identification of the triggering factors, may contribute to change the legal framework of civil protection and governance policies (Mendes \& Tavares, 2009).

\section{METHODOLOGY AND RESULTS}

In this article we present an evaluation of social vulnerability for all municipalities in Portugal, taking the national framework as reference, and also an evaluation of social vulnerability at the town level within a regional framework. One variable can be irrelevant at the municipal scale, but be very important at the town scale. Furthermore, scale is not only relevant for the unit of analysis used in research but also an issue of compatibility with decision making (Eakin 2006). As the national level allows the formulation of strategic and structural recommendations, the municipal level sets the basis for urban and emergency planning; the town levels are useful to delineate specific intervention and mitigation actions. The ideal scenario is an articulation between different scales.

The issue of scale and the reliability of social vulnerability indexes has been recently discussed by Schmidtlein et al. (2008). They conclude that 
“...while scalar changes affect PCA analysis and the numeric properties of the index, the identification of the drivers of vulnerability within a study area, based on a constant variable set, are not strongly dependent on the scale of aggregation used to define the study area" (Schmidtlein et al., 2008). In this paper for the same variable set we test the models at different scales and context frameworks.

Following the line advocated by authors like Prescott-Allen (2001), OECD (2003) and Eakin (2006) in the assessment of vulnerability, the humanenvironment interactions are taken into account. We think that it may not be methodologically correct to mix in the same dimension individual and structural characteristics which influence the levels of social vulnerability. Thus, the social vulnerability evaluation is based on a two step analysis, described as criticality and support capability of the territorial system.

In the territory a wide set of activities (transports, industry and agriculture) occurs that pressure the environment (air, water, soil). That's what we call the territorial system. A system is considered as any nongrowth entity that generates outputs from inputs, under the control of a human agent. The agent uses system resources that are in the environment, enabling the generation of a mean output per unit time from a set of inputs (Bradley, 2007). The crisis happens when the system breaks down, so the critical point and consequently, the acceptable limits of well-being are overreached.

Thus, criticality is defined as the ensemble of individuals' characteristics and behaviours that may contribute to the system's rupture. However, the community may have territorial resources that will allow responding to dangerous events or processes or deal with a catastrophic scenario. So, besides criticality we will have to take into account support capabilities in the territory, defined as the set of territorial infrastructure that enables the community to react in case of disaster.

Authors like Pelling (2003) defend that urban vulnerabilities are developed in consequence of interdependencies that occur between economic activity, transportation and residential areas. In this paper we present a vulnerability analysis that incorporates the interdependencies between environmental and societal structures.

The levels of criticality and support capabilities of the territorial system were assessed using an original set of 138 variables, divided by the following groups: buildings, civil protection, demography, economy, education, justice, health, housing, social support, and environmental support.

To these normalised variables, it was applied a factor analysis, based on a principal components analysis (PCA), using the SPSS statistical package. Applying a varimax rotation, all factors with eigenvalues greater than 1.00 were retained.

In the subsequent phase, all factors were scaled so that positive values indicated higher levels of criticality and support capability, and negative values decreased the levels of criticality and support capability.
The final data was ranked according to five categories of social vulnerability: very high ( $>1$ standard deviation related to the mean value of the equation's final result); high ( $0.5-1$ standard deviation); moderate $(-0.5-0.5$ standard deviation); low (form -1 to -0.5 standard deviation); very low $(<-1$ standard deviation) (see Cutter et al., 2004).

\subsection{Methodology-Criticality at the municipal scale}

The criticality's evaluation was based on 96 variables. Those were reduced to 56 in result of a multicollinearity analysis and, after the factorial analysis, 22 variables were retained (Table 1).

Based in the 22 explanatory variables, 6 factors were retained. These factors explain $76 \%$ of the variance among all Portugal's municipalities, with a Kaiser-Meyer-Olkin measure of sampling adequacy (KMO) of 0.756 , and with all communalities above 0.6 .

The first factor explains $29 \%$ of the variance and it is the related to the demographic structure. The older the population of the municipality, the higher will be its score on the first factor.

The second factor explains $19 \%$ of the variance and is associated with the economic strength of the municipalities. The higher the economic strength, the lower the level of criticality will be, as communities with more resources will be able to solve damages provoked by an event like a flood.

The third factor explains $10 \%$ of the variance and characterizes the building conditions, with particular emphasis on building ages. The period that buildings were constructed and their inherent structural characteristics are important, and it is assumed that the newer the building, the better its quality and structural resilience will be to natural dangers. Also, building codes and rules are stricter in Portugal after 1980.

The fourth factor explains $7 \%$ of the variance and focuses on the professional structure of the working population. It is an indicator of the population's economic power and skills.

The fifth and sixth factors explain $6 \%$ and $5 \%$ of the variance respectively, and are related with the economic factors. The fifth characterizes individuals who

Table 1. Number of variables used in criticality's evaluation at the municipal scale.

\begin{tabular}{llll}
\hline \multirow{2}{*}{ Groups } & $\begin{array}{l}\text { Variables } \\
\text { Initial }\end{array}$ & Model & Explanatory \\
\hline Building conditions & 11 & 9 & 3 \\
Demography & 11 & 7 & 2 \\
Economy & 26 & 13 & 9 \\
Education & 8 & 3 & 2 \\
Housing & 11 & 8 & 4 \\
Justice & 6 & 0 & 0 \\
Social Support & 23 & 16 & 2 \\
Total & 96 & 56 & 22 \\
\hline
\end{tabular}




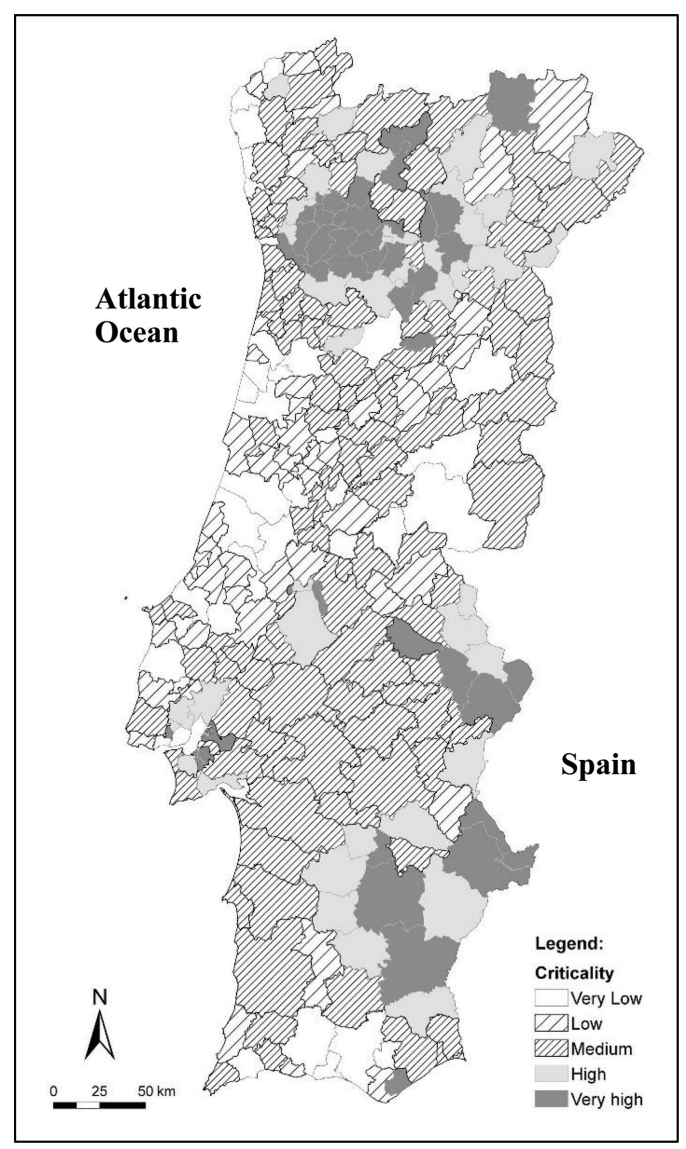

Figure 1. Municipal criticality in portugal.

receive the guaranteed minimum income. The sixth factor reflects the economy's dynamic.

\subsection{Results - Criticality at the municipal scale}

Figure 1 shows the criticality at the municipal level in Portugal. Very low levels of criticality are concentrated essentially along the coastal strip, in the north, in the Centre and in the Region of Algarve. The central region also presents a global distribution of the lowest critical levels, including the interior areas. It is important to say that the reasons why, for instance, Lisbon presents low levels of criticality are different from those of Viana do Castelo, which is a coastal municipality in the North. In the capital the final result of the equation is determined by the high economic power of the population, and in Viana do Castelo the final result of the equation is determined by the index of building conditions.

The highest levels of criticality are concentrated in a group of municipalities in the Northern of Portugal, and also in municipalities of the border south of Alentejo. In the North, the high levels of criticality are mainly determined by the low economic strength of the population, with particular emphasis on factor 5 (percentage of beneficiaries of a guaranteed minimum
Table 2. Number of variables used in support capability at the municipal scale.

\begin{tabular}{llll}
\hline Groups & $\begin{array}{l}\text { Variables } \\
\text { Initial }\end{array}$ & Model & Explanatory \\
\hline Buildings & 11 & 9 & 0 \\
Civil Protection & 27 & 7 & 2 \\
Economy & 86 & 27 & 4 \\
Health & 10 & 10 & 3 \\
Housing & 11 & 8 & 1 \\
Total & 145 & 61 & 10 \\
\hline
\end{tabular}

income). In the South, the high levels of criticality presented are due both to factor 3 (building conditions), but also to factor 4 (professional structure of the working population).

\subsection{Methodology-Support capabilities at municipal scale}

In the primary phase of support capability evaluation 145 variables were taken into account.

Through factorial analysis it was possible to conclude that from the 61 variables included in the model, 10 variables were sufficient to explain the model (Table 2).

From the evaluation of the support capabilities at the municipal scale 4 factors were retained, which explain $71 \%$ of the variance, with a KMO of 0.7 and with all communalities above 0.6 .

The first factor explains $31 \%$ of the variance and reflects the economic and environmental dynamism of the municipality. The higher the dynamism, the greater will be the support capability.

The second factor explains $17 \%$ of the variance and is related with one of the most important aspects concerning support capabilities to natural and technological disasters: the number of firefighters' corporations.

The third factor explains $12 \%$ of the variance, and its score results from the logistical capacity and presence of insurance companies in the territory.

The fourth factor explains $10 \%$ of the variance, and is represented by only one variable, which is "pharmacies per 10000 inhabitants".

\subsection{Results - Support capability at the municipal scale}

The output map of the municipal support capabilities in Portugal is presented in Fig. 2. We can observe a distribution of the lowest levels of support capability in the Northern part of the country, and the highest levels in the interior and in the Algarve region. The weak economic dynamics (factor 1) are relevant in the Northern and Central municipalities for the very low support capability. However, some low levels of municipal support capability are explained by the influence of factor 3 (logistical capacity and insurance activity in the territory) or by factor 4 (density of pharmacies in the territory). 


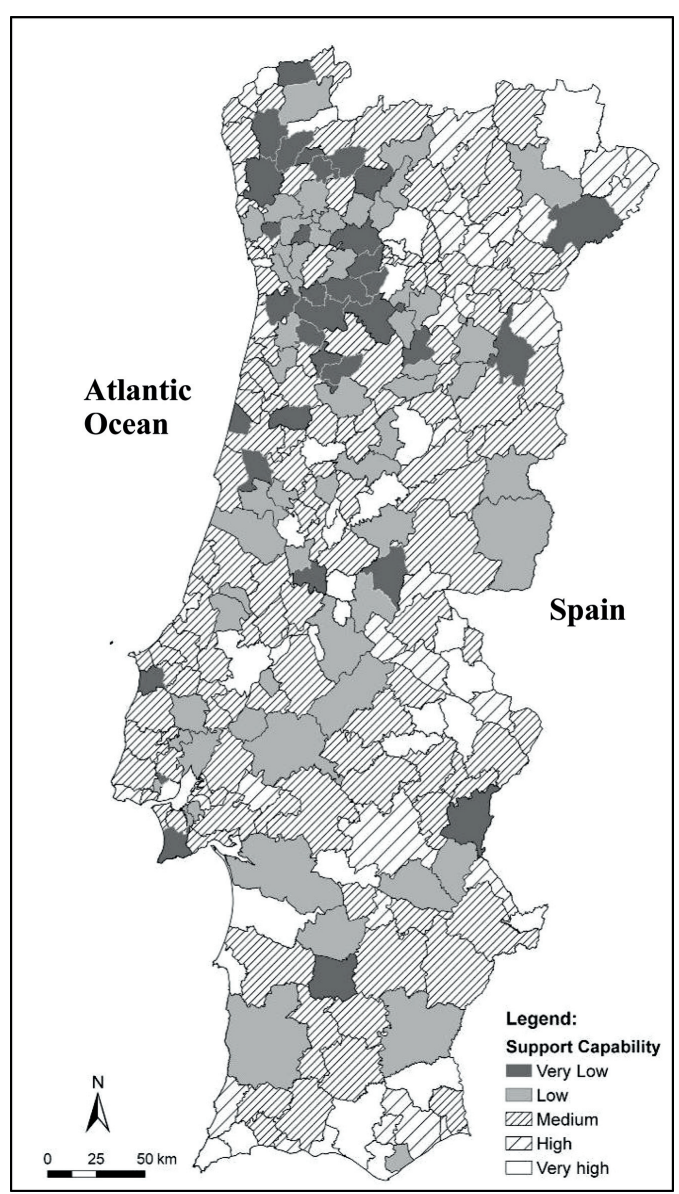

Figure 2. Support capability by municipalities in portugal.

The economic dynamic (factor 1) and pharmacies (factor 4) were decisive to some urban municipalities such as Lisbon, Porto, Loulé and Santarém which have a very high level of support capability.

\subsection{Methodology-Criticality at town scale}

To test our two social vulnerability components, criticality and support capability, and the resulting social vulnerability indexes as influenced by scalar variation, we selected seven municipalities from the Centre Region of Portugal (Ovar, Coimbra, Marinha Grande, Nelas, Almeida and Proença-a-Nova). These are seven municipalities quite different in biophysical and socioeconomic aspects. We focused on nine features to make these municipalities representative of the 72 municipalities of the Centre region of Portugal. The sampling took into account the location (coastal and interior, as it is possible to see in Fig. 3), the municipality's total area, the number of inhabitants, the population density, the number of towns, the rural and urban land use, and the relevance of the industrial, agro-forestry and tertiary activities.

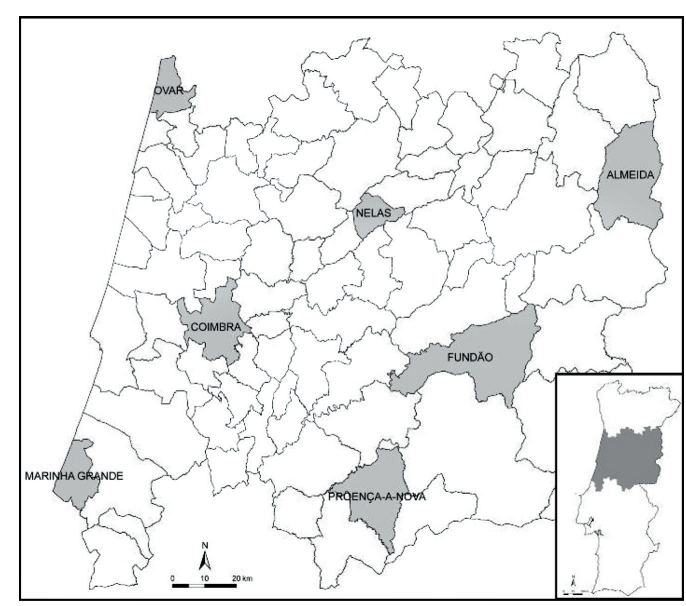

Figure 3. Geographical location of the seven municipalities selected as sample.

Table 3. Number of variables used in criticality's evaluation at town scale.

\begin{tabular}{llll}
\hline & \multicolumn{2}{l}{ Variables } & \\
\cline { 2 - 4 } Groups & Initial & Model & Explanatory \\
\hline Buildings & 11 & 8 & 1 \\
Demography & 14 & 10 & 4 \\
Economy & 30 & 21 & 1 \\
Housing & 11 & 4 & 0 \\
Social Support & 13 & 10 & 0 \\
Total & 79 & 53 & 6 \\
\hline
\end{tabular}

The criticality's evaluation of these municipalities at the town scale was based on 79 variables. After the factorial analysis, it was possible to conclude that 6 variables were enough to explain the model. Table 3 summarizes the number and distribution of the variables included in the analysis process.

In the evaluation of criticality at the town scale, 3 factors were retained, which explain $78 \%$ of the variance. The sample's KMO is 0.617 and all communalities have a value above 0.6 .

In the first factor, which explains $40 \%$ of the variance, the dominant variable is the unemployment rate, followed by variables concerning demographic structure. We can say that the first factor aggregates socially vulnerable groups.

The second factor, which explains $21 \%$ of the variance, is focused on a specific socially vulnerable group: people with handicaps, with particular relevance to the percentage of resident population with an assigned degree of disability exceeding $80 \%$.

The third factor, which explains $17 \%$ of the variance, is constituted only by the percentage of buildings constructed before 1960 . This factor is useful in the identification of more consolidated urban areas. 
Table 4. Criticality at town scale - Dispersion statistics.

\begin{tabular}{lllll}
\hline Municipality & Average & Minimum & Maximum & $\begin{array}{l}\text { Standard } \\
\text { deviation }\end{array}$ \\
\hline Almeida & 1,82 & $-1,1$ & 5,76 & 1,81 \\
Coimbra & 0,89 & $-1,48$ & 5,32 & 1,79 \\
Fundão & 0,02 & $-2,3$ & 2,33 & 1,02 \\
Marinha & 0,47 & 0,04 & 0,9 & 0,35 \\
Grande & & & & \\
Nelas & 0,2 & $-1,63$ & 2,47 & 1,23 \\
Ovar & 1,14 & 0,68 & 1,79 & 0,43 \\
Proença-a- & 0,2 & $-0,36$ & 0,98 & 0,43 \\
Nova & & & & \\
Total & 0,8 & $-2,3$ & 5,76 & 1,6 \\
\hline
\end{tabular}

Table 5. Number of towns with the lowest and the highest levels of criticality.

\begin{tabular}{llll}
\hline Municipality & $\begin{array}{l}\text { Number } \\
\text { towns }\end{array}$ & $\begin{array}{l}\text { Towns with } \\
\text { the lowest } \\
\text { level }\end{array}$ & $\begin{array}{l}\text { Towns with } \\
\text { the highest } \\
\text { level }\end{array}$ \\
\hline Almeida & 29 & 1 & 11 \\
Coimbra & 31 & 3 & 7 \\
Fundão & 31 & 5 & 0 \\
Marinha Grande & 3 & 0 & 0 \\
Nelas & 9 & 2 & 1 \\
Ovar & 8 & 0 & 0 \\
Proença-a-Nova & 6 & 0 & 0 \\
Total & 117 & 11 & 19 \\
\hline
\end{tabular}

\subsection{Results - Criticality at town scale}

In the Table 4 we can observe the basic statistic results of the criticality in the seven municipalities, according to the town dispersion data.

Concerning the high levels of criticality, the municipalities of Coimbra and Almeida are evinced. The third factor plays an important role in the historical towns located in central city of Coimbra, which concentrate a high percentage of aging population, confirming that this factor is useful for the identification of more consolidated urban areas.

The two municipalities with the lowest average value of criticality and that are more homogeneous (low standard deviation) are Marinha Grande and Proença-a-Nova. Marinha Grande is a coastal municipality with important industrial activities. Proençaa-Nova is an interior municipality with an important agro-forestry sector. As these two municipalities have very contrasted socio-demographic and socioeconomic characteristics, we can conclude that criticality is not directly related to urbanisation or dominant economic activities.

In the Table 5 we present the number of towns in the municipal context which present contrasted values of criticality. This element stresses at municipal level the heterogeneity of the communities and individuals in case of a disastrous event. Almeida and Coimbra
Table 6. Number of variables used in support capability evaluation at town scale.

\begin{tabular}{llll}
\hline & \multicolumn{2}{l}{ Variables } & \\
\cline { 2 - 4 } Groups & Initial & Model & Explanatory \\
\hline Buildings & 11 & 8 & 0 \\
Economy & 59 & 15 & 2 \\
Energy Supply & 2 & 2 & 0 \\
Health & 2 & 2 & 1 \\
Housing & 11 & 4 & 1 \\
Social Equipments & 5 & 3 & 2 \\
Water Supply & 10 & 10 & 3 \\
Total & 100 & 44 & 9 \\
\hline
\end{tabular}

municipalities show a contrasted territory in opposition with the results from Marinha Grande, Ovar and Proença-a-Nova.

The Almeida municipality presents the highest value in terms of criticality, due mainly to a high percentage of handicapped population with an assigned degree of disability exceeding $80 \%$. Concerning maximum values, Almeida is followed by Coimbra, a city with an historical area with a high proportion of buildings constructed before 1960 .

In the municipality of Almeida 11 of the towns present the highest level of criticality, a fact that denotes it as one of the most depressed municipalities in Portugal.

\subsection{Methodology-Support capability at the town scale}

In support capability's evaluation at the town scale, 100 variables were collected, although only 44 were included in the model. In Table 6 we can observe the number of variables to analyse support capability in the seven studied municipalities.

In the evaluation of support capability 4 factors were retained. These factors explained $73 \%$ of the variance and all communalities were above 0.5 .

The first factor, which explains $28,4 \%$ of the variance, is related with the towns water system performance.

The second factor, which explains $18.6 \%$ of the variance, is related with social equipments like day centre facilities and kindergartens, that are crucial in diminishing the vulnerability to hazards in these group ages (Mendes, 2009).

The third factor, which explains $14.5 \%$ of the variance, is focused in CAE - $\mathrm{D}^{1}$, specifically about its impact in the economy.

The fourth factor, which explains $11.6 \%$ of the variance, has only one variable, that is pharmacies per 1000 persons.

\footnotetext{
${ }^{1}$ This is a classification of economic activities set by the Portuguese National Institute of Statistics, which covers all the activities related with electricity, gas, steam.
} 


\subsection{Results - Support capability at town scale}

In Table 7 we can observe the basic statistic results of the supported capability in the seven municipalities, where the town dispersion data is presented.

The highest value of support capability is observed in Nelas, due to the economic activities and industrial production that are present in this municipality.

By the analysis of Table 7, we can see that Coimbra is the municipality that has a town with the lowest level in terms of capability support, due to its low score in factor 1 - water system performance. In Table 8 we can observe that Coimbra presents a deep territorial contrast in terms of capability support, in opposition with Fundão, and Proença-a-Nova municipalities. The results of the Almeida municipality stress the relevant capability support in five towns, deriving from its high score in factor 1.

In the whole, it is possible to conclude that there are more towns with a highest level of capability support than towns with a lowest level, which can be read as a good indicator of the resistance capability of local communities to the impact of natural and technological disasters. The role of the municipal governments, mainly after the Carnation revolution of 1974, has to be emphasized. Also, after Portugal integration in the European Union in 1986, many structural funds were

Table 7. Support capability at town scale - Dispersion statistics.

Standard

Municipalities Average Minimum Maximum deviation

\begin{tabular}{lllll}
\hline Almeida & 0,6 & $-1,39$ & 5,88 & 1,63 \\
Coimbra & $-0,45$ & $-2,40$ & 7,83 & 2,47 \\
Fundão & $-0,43$ & $-1,77$ & 1,47 & 0,85 \\
Marinha & 1,8 & $-0,46$ & 2,94 & 1,59 \\
Grande & & & & \\
Nelas & 0,72 & $-1,91$ & 9,24 & 3,41 \\
Ovar & 0,2 & $-1,03$ & 2,92 & 1,23 \\
Proença-a- & $-0,67$ & $-1,88$ & 1,6 & 1,22 \\
Nova & & & & \\
Total & 0 & $-2,4$ & 9,24 & 1,99 \\
\hline
\end{tabular}

Table 8. Number of towns with the lowest and the highest level of capability support.

\begin{tabular}{llll}
\hline & Number & $\begin{array}{l}\text { Number of } \\
\text { towns with } \\
\text { the lowest } \\
\text { level }\end{array}$ & $\begin{array}{l}\text { Number of } \\
\text { towns with } \\
\text { the highest } \\
\text { level }\end{array}$ \\
\hline Almeida & 29 & 0 & 5 \\
Coimbra & 31 & 6 & 4 \\
Fundão & 31 & 0 & 0 \\
Marinha Grande & 3 & 0 & 2 \\
Nelas & 9 & 0 & 2 \\
Ovar & 8 & 0 & 1 \\
Proença-a-Nova & 6 & 0 & 0 \\
Total & 117 & 6 & 14 \\
\hline
\end{tabular}

used to ameliorate infrastructures, roads and living conditions in the Portuguese municipalities.

The differences captured by the support capability measures highlight the heterogeneous territorial structure of the Centre region of Portugal, mitigated by policy interventions of the municipal governments in capturing private sector investments and fostering proactive incentives to infrastructural development.

\section{CONCLUSION}

In this paper we presented a new version of social vulnerability indexes to natural and technological hazards that takes into account, beyond the standard analysis of exposure or biophysical vulnerability, social resilience and infrastructural support capabilities.

This is in line with the proposition of Schmidtlein et al. (2008) that there is a need to integrate social science research concerning social vulnerability into emergency and risk decision management. It was our argument in this paper that this integration has to take into account the role of scale and the dynamics of the territories at different levels of analysis.

We presented two scalar approaches to territorial social vulnerability. The methodology to assess vulnerability was based on factorial analysis, with the incorporation of the human-environment interactions. This approach allowed for the composition of vulnerability into two dimensions: the vulnerabilities of the persons and communities (criticality) and the territorial vulnerability (support capability). As an example, we can point the case of Santo António dos Olivais, a town from the city of Coimbra. With more than 30,000 inhabitants, it has high percentages of families consisting of individuals aged 65 and over and also of resident population aged less than 5 years, both facts concurring for this town to have a high level of criticality. However, this town also presents higher levels of support capability, due to its dense and diversified network of social, health, cultural and educational equipments. These latest aspects are crucial in risk mitigation strategies.

Nevertheless, place and scale matters, and this implies that a model that works well in a place, probably won't work so well in another place. Each place has its own socioeconomic, political and cultural characteristics. As we could see, previously, the factors that influence the final result of the equation differ from place to place, according with theframework of reference used in the analysis (the national or the regional). Nevertheless, the overall model is consistent in different scales, allowing to the elaboration of adapted and specified strategies of risk mitigation and civil protection measures.

The mapping of vulnerability allows for the comparison between places, both in criticality and capability support, enabling therefore better resources management and specific oriented public policies.

It is also important to say that the variables used at the municipal scale return a different reality that those 
used at the town scale. The aims that drive a municipal analysis are different from those that guide an analysis at town scale.

The criticality and support capacity evaluation, presented in this article, take part of a more embracing vulnerability's evaluation, in which stakeholders and the population knowledge and perceptions must be taken into account.

A good vulnerability assessment, integrating both criticality and support capability, will provide better preparedness, response and mitigation strategies.

\section{REFERENCES}

Cutter, S., Boruff, B, Shirley,W. 2003. Social vulnerability to environmental hazards. Social Science Quarterly 84: 242-61.

Davis, I. 2004. Progress in Analysis of Social Vulnerability and Capacity in Greg Bankoff (Eds) Mapping Vulnerability Disasters, Development \& People, 128-44. London: Earthscan.

Emergency Management Australia. 2002. Planning Saffer Communities - Land use planning for natural hazards http://www.ema.gov.au/www/emaweb/rwpattach.nsf/ VAP/(3273BD3F76A7A5DEDAE36942A54D7D90) $\sim$ Manual07-PlanningSaferCommunities.pdf/\$file/ Manual07-PlanningSaferCommunities.pdf Accessed on 17 November 2007.
Eakin, H., Luers A. L. 2006. Assessing the Vulnerability of Social - Environmental Systems. Annu. Rev. Environ. Resour. 31: 365-94.

Mendes, J.M. 2009. Social vulnerability indexes as planning tools: beyond the preparedness paradigm. Journal of Risk Research, 12: 1, 43-58.

Mendes, J. M.; Tavares, A. 2009. Building resilience to natural hazards. Practices and policies on governance and mitigation in the central region of Portugal. Safety, Reliability and Risk Analysis: Theory, Methods and Applications. Ed. Martorell et al. Taylor and Frances Group, 2008: 1577-1584.

Organisation for Economic Co-Operation and Development. 2003. Environmental Indicators Development, Measurement and Use http://www.oecd.org/dataoecd/7/47/ 24993546.pdf Accessed on 15 February 2009.

Pelling, M. 2003. The vulnerability of cities: Natural Disasters and Social Resilience. London: Earthscan.

Prescott-Allen, R. 2001. The Wellbeing of Nations: A Country-by-Country Index of Quality of Life and the Environment, Island Press.

Ribeiro, M.J. 1995. Sociologia dos desastres, Sociologia, Problemas e Práticas 18: 23-43. Lisbon: Centro de Investigação e Estudos de Sociologia - ISCTE.

Schmidtlein, M. Deutsch, R. Piegorsch,W. Cutter, Susan. 2008. A sensitivity analysis of the social vulnerability index. Risk Analysis, Vol.28, n. ${ }^{\circ}$ 4, 1099-1114.

United Nations Organization 2004. Living with Risk A Global Review of Disaster Reduction Initiatives. http:// www.unisdr.org/eng/about_isdr/bd-lwr-2004-eng.htm Accessed on 1 March 2009. 